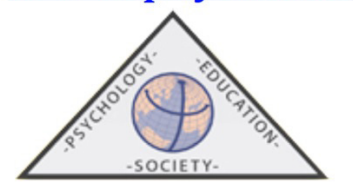

\title{
Achievement Goal Orientations and Perceived Physical Competence Profiles in Adolescent Physical Activity
}

\author{
Simona NICOLOSI ${ }^{1,2}$, Rosario ORTEGA RUIZ ${ }^{2}$ y Juan de Dios BENITEZ SILLERO ${ }^{2}$ \\ ${ }^{1}$ Università degli studi di Enna Kore \\ ${ }^{2}$ Universidad de Córdoba
}

(Received April 20, 2020, Accepted December 16, 2020)

\begin{abstract}
The objective of this study was to analyze the relationships between achievement goals and perceived physical competence in a sample of 4493 adolescents between 12 and 18 years of age $(\mathrm{M}=14.92, \mathrm{SD}=2.08)$. A cluster analysis was performed to (1) identify cluster profiles of the adolescents based on their goal orientations and perceived physical competence, and (2) assess whether clusters differed in gender, age, and participation in physical activity.

Three stable clusters reflecting different achievement goals and perceived physical competence profiles were identified: high, moderate, and low task orientation and perceived competence. Differences were found in genders, age, and physical activity frequency. The discussion focuses on the implications for educators, physical education teachers, and coaches and provides information for possible strategies to foster physical activity in adolescents.
\end{abstract}

Keywords: Task, Ego, Physical Self-Concept, Achievement, Cluster Analysis.

\section{Perfiles de orientación de metas y competencias físicas percibidas en la actividad fisica de los adolescentes}

RESUMEN: El objetivo de este estudio fue analizar las relaciones entre las metas de logro y la competencia física percibida en una muestra de 4493 adolescentes entre 12 y 18 años de edad $(\mathrm{M}=14.92$, $\mathrm{DE}=2.08$ ). Se realizó un análisis de conglomerados para (1) identificar los perfiles de conglomerados de los adolescentes en base a sus orientaciones de metas y su competencia física percibida, y (2) evaluar si los conglomerados diferían en género, edad y participación en la actividad física.

Se identificaron tres conglomerados estables que reflejaban diferentes objetivos de logro y perfiles de competencia física percibida: orientación a las tareas alta, moderada y baja, y competencia percibida. Se encontraron diferencias en cuanto al género, la edad y la frecuencia de la actividad física. La discusión se centra en las implicaciones que estos resultados podrían ofrecer a educadores, los profesores de educación física y los entrenadores, proporcionando información sobre posibles estrategias para fomentar la actividad física en los adolescentes.

Palabras clave: tarea, ego, autoconcepto físico, logro, análisis Cluster. 
Correspondencia: Simona Nicolosi. Viale delle Olimpiadi, 94100 Enna EN, Italia. E-mail: simona.nicolosi@unikore.it

\section{Introduction}

Regular participation in physical activity in childhood and adolescence contributes to the acquisition and maintenance of physically and psychologically healthy habits, affecting physical competence and motivation (Piercy et al., 2015; Zurita-Ortega et al., 2016). However, during the first years of adolescence, a decline in levels of physical activity, perceived competence, and motivation has been observed, especially in girls (Moreno Murcia, Hellín, Hellín, Cervelló, \& Sicilia, 2008).

Potential barriers to participation in physical activities in children are constituted by low actual and perceived physical competence, low physical fitness levels, and obesity (Khodaverdi, Bahram, \& Robinson, 2015). Different studies sustained that perceived competence and aerobic fitness mediate the relationship between actual motor skills and physical activity (Marsh, 2007; Barnett, Morgan, van Beurden, \& Beard, 2008; Barnett, Van Beurden, Morgan, Brooks, \& Beard, 2009). Furthermore, it has been shown that actual motor competence can promote a positive association among perceived motor competence, physical activity, and physical fitness in childhood and adolescence (Stodden et al., 2008). In this relationship it is possible that a positive or a negative spiral of healthy behaviors in young people may be produced. Then, the need to analyze antecedent and consequent mechanisms of why individuals choose to be active or inactive is fundamental (Stodden, et al., 2008).

\section{Achievement goal theory}

Achievement goals concern how people construct their competencies and guide their behavior to achieve objectives. When an individual starts an activity, following certain goals reflects personal perceptions and beliefs about that achievement situation and the form of ability he/she wants to demonstrate. For this reason, the manner in which people perceive and value their own ability is crucial. A major aspect of achievement situations is the demonstration and development of competence (Duda, 1992). In the sports context, the sense of accomplishment seems to depend on the necessity of achieving performance, expressing one's own abilities, and comparing one's competencies with those of one's opponents. According to Nicholls (1989), two different achievement goals operate in achievement contexts like sport: task and ego goals.

When an individual is engaged in a task, he or she tends to use an undifferentiated conception of ability, featured by high emphasis on the learning process and low social comparison.

A task-involved person defines success as the development of abilities in terms of control or improvement in the execution of a task and tends to adopt self-referenced evaluation criteria of ability; perceived ability is less relevant because the individual is focused more on the execution of the task. Success, from a task-involved perspective, means having a better performance than before.

On the other hand, a more differentiated conception of ability as capacity is used in a situation characterized by high evaluation, such as a sport competition or interpersonal comparison. In- 
dividuals are said to be ego-involved when this differentiated conception of ability is activated (Nicholls, 1989; Roberts, Treasure, \& Conroy, 2007).

An ego-involved person is focused on the demonstration of abilities as normative and shows a special interest in winning, especially with little effort. If the individual has a high perception of his/her own abilities, he/she will try to show himself/herself to be more competent than others or at least not to appear incompetent. If the individual has a low perception of his/her own abilities, he/she will adopt maladaptive behaviors, such as avoiding the task, giving up physical activity, or cheating to win a match (Roberts et al. 2007; Cecić Erpič, 2011).

The predispositions to act in an ego- and/or task-involved way are called achievement goal orientations. Task and ego orientations have been demonstrated to be orthogonal, then a person can show different levels in both dimensions (Roberts et al., 2007). Nicholls (1989) proposed that ego goal orientations are connected with perceptions of competence, because an ego-oriented person is concerned with normative ability and refers their performance to other people. Then, it is likely that he or she displays higher levels of motivation when perceiving their competence to be high, but lower levels of motivation when perceiving their competence to be low. A task-oriented person on the other hand is concerned with self-improvement and personal effort and will be driven to make an effort, independently of the level of competency perceived, whether high or low (Roberts et al. 2007; Cecić Erpič, 2011).

A task orientation has been associated to a higher likelihood of endorsing adaptive behaviors, such as cooperation with others, fair play, and positive attitudes concerning participation in sports and exercise (Walling \& Duda, 1995; Hodge \& Petlichkoff, 2000).

In a school context, a task orientation is associated with the goals of physical education, such as skill development, commitment to the task, and collaboration with classmates. On the contrary, an ego orientation is associated with the belief that the goal of physical education is to provide easy lessons, learn to be competitive, and learn how to cheat (Papaioannou \& Mc Donald, 1993; Walling \& Duda, 1995; Mouratidou, Goutza, \& Chatzopoulos, 2007; Gonçalves, Coelho e Silva, Cruz, Torregrossa, \& Cumming, 2010; Ring \& Kavussanu, 2018).

As much in sports as in physical education, task goals are positively associated with adaptive achievement strategies, with the belief that effort causes success and positive effects (Biddle \& Wang, 2003). In contrast, an ego orientation is related to the belief that athletic success is a result of superior ability and to the view that success was achieved through misleading tactics, such as cheating and manipulating the coach (Walling \& Duda, 1995).

A task orientation could lead to the development of abilities and subjective perception of physical competencies: a youth who is committed to improving his abilities and who is conscious of his progress also recognizes that these improvements are the result of his efforts and persistence in pursuing set goals in a training program (Roberts et al., 2007). However, some authors have argued that a high ego orientation may not be motivationally maladaptive. When an ego orientation is combined with a task orientation, the motivation profile can be adaptive (Wang \& Biddle, 2001; Hodge \& Petlichkoff, 2000). According to Wentzel (1991), achievement in the school context may depend on the ability to be flexible in choosing one orientation or even both in an appropriate situation. 


\section{Achievement goal theory and perceived physical competence profiling}

Different studies have noted that in adolescence goal orientation (mastery) and the perception of physical competence have the greatest influence on all behaviors related to physical activity (Sterdt, Liersch, \& Walter, 2014; Martins, Marques, Peralta, Palmeira, \& da Costa, 2017).

A few studies have analyzed the relationship between achievement goals and perceived physical competence with cluster analysis (Wang \& Biddle, 2001; Wang, Chatzisarantis, Spray, \& Biddle, 2002; Moreno Murcia, Llamas, \& Ruiz, 2006; Moreno Murcia et al., 2008; Wang, Liu, Sun, Lim, \& Chatzisarantis, 2010).-

Wang and Biddle (2001) involved a large sample of adolescents from 12 to 15 years old and identified five profile groups (self-determined, highly motivated, lowly motivated, moderately motivated externals, and amotivated). High task groups had high perceived competence and physical self-worth, and were more active in physical activity participation. The older girls were more represented in the cluster with low perceived competence and low task orientation, confirming that these motivational patterns need attention for intervention.

In the study by Wang et al. (2002), three profiles emerged from cluster analysis: lowly, moderately and highly motivated. The highly motivated group displayed high perceived competence, together with the highest physical activity levels. This group contained the smallest number of females (only $37.5 \%$ ) but there were no gender differences in the lowly motivated group.

Biddle and Wang (2003) have shown results of a cluster analysis that aimed to define motivational profiles in adolescent girls from 11 to 16 years old. A five-cluster solution emerged from data mirroring various combinations of motivational and physical self-perceptions. Forty percent is represented by the group with moderate scores in motivation and physical self. The remaining $60 \%$ was distributed in four clusters, $30 \%$ had negative profiles (amotivated; very low motivation and low physical self) and the other $30 \%$ had positive profiles (high motivation and physical self; moderate motivation and high physical self).

Moreno Murcia et al. (2008) found four motivational profiles in Spanish physical education students (highly motivated; non-self-determined; moderate self-determined; amotivated). Results showed that both task orientation and ego orientation were related to perception of competence and physical condition subscales. In the highly motivated cluster, the highest levels of task and ego orientation were related to the highest values of perceived competence and sport/physical activity outside school hours. In the highly motivated cluster a greater number of boys was present, whilst in the amotivated cluster the percentage of girls and physically inactive students was slightly higher than in the boys'. In this study and in Biddle and Wang (2001) with British adolescents between 12 and 15 years old, in the non-self-determined profile there was a positive relation among a moderate level of external motivation, ego orientation, participation in sport/ physical activity outside school, global physical self-evaluation, and perceived competence.

Wang et al. (2010) examined motivation toward physical education in a sample of Chinese students from 11 to 19 years. Authors identified four clusters with a cluster analysis. A first goal 
profile was defined highly motivated, with high levels of perceived competence; two profiles were moderately motivated, the second with high perceived competence and the third with low perceived competence; a fourth profile was lowly motivated, with low perceived competence. The latter two seem to be the worst in terms of achievement goals and physical activity participation. Significant gender differences were found; there were more males than females in the first and second cluster but more females than males in the third cluster.

In these studies, age differences were not analyzed and physical competence was measured as a whole.

In previous research, the highest percentage of girls and physically inactive students was usually found in the low motivation clusters and task-oriented groups (Wang et al., 2002; Moreno Murcia et al., 2006; McNeill \& Wang, 2005; Wang \& Biddle, 2001), with the exception of the study by Moreno Murcia et al. (2008). These results are troubling concerning physical education and these groups need attention in classes. As suggested by Wang and Biddle (2001), intervention will be more effective when we have information on the different target groups we might be trying to change.

In various studies, there emerges the importance of considering how the two goal orientations complemented one another to lead to adaptive behaviors in the sports context (Hodge \& Petlichkoff, 2000), as well as in physical education and physical activity settings (Moreno Murcia et al., 2008; Wang, Liu, Sun, Lim, \& Chatzisarantis, 2010). Although the results relating to task goal orientation are associated with a better perception of physical competence, those relating to a high ego orientation are less clear (Biddle \& Wang, 2003). In Hodge and Petlichkoff's study (2000), it emerged from a study on athletes that the balance between the two orientations could strengthen both the ego-involved with their "winning focus" and the task-involved with their "how to win" approach.

In the physical education school context, Wang et al. (2010) showed that students with moderate task orientation, moderate ego orientation, and high perceived competence could also show adaptive patterns similar to the students with high task orientation.

Given the literature reviewed above, the first purpose of this study was to identify cluster profiles of the adolescents based on their goal orientations and perceived physical competence in physical education classes.

Following this, the second purpose consisted of testing the differences between clusters regarding gender, age, and frequency of participation in physical activity outside required school physical education lessons.

The initial hypothesis was that adolescents with higher levels of perceived physical competence and higher task goal orientation are more involved in physical activities outside physical education lessons, compared to their peers who are less involved or are not involved at all in physical activity outside physical education lessons. Furthermore, we hypothesized that females have lower levels of perceived competence, goal orientations, and participation in physical activities outside school physical education than males. Finally, we tested whether, as age increased, the decline in goal orientations and perceived competence is more evident in females than in males. 


\section{Method}

\section{Design and participants}

The participants in the study were 4939 adolescents from 12 to 18 years of age from 16 junior high schools and 29 high schools in Sicily (the South of Italy). A cross-sectional study design with a cluster sampling method was used. The participants were involved through a random selection of the schools in the targeted area of the study.

The sample size calculation was performed with a significance level of 0.05 . Thus, the sample size revealed that 4338 participants would obtain an $80 \%$ power (Fabbris, 1989). A higher number of participants was involved in order to prevent possible elimination of data by detection of not valid or missing response.

A total of 4939 questionnaires were gathered. A total of 200 of these were excluded because they were considered not valid or with missing data; 246 were excluded for not meeting the age requirement.

Thus, there were 4493 valid questionnaires, of which 1917 were boys and 2576 girls between 12 and 18 years of age $\left(\mathrm{M}_{\text {age }}=14.92, \mathrm{SD}_{\text {age }}=2.07\right)$. Descriptive characteristics of the participants are shown in Table 1.

Table 1. Participants by gender and age groups

\begin{tabular}{|c|c|c|c|c|c|c|c|c|c|c|c|c|c|c|c|c|c|c|}
\hline \multirow{3}{*}{ Age groups } & \multicolumn{12}{|c|}{ Gender } & \multirow{2}{*}{\multicolumn{6}{|c|}{ Total }} \\
\hline & \multicolumn{5}{|c|}{ Males } & \multicolumn{7}{|c|}{ Females } & & & & & & \\
\hline & & & f & $\%$ & $\mathbf{M}_{\text {age }}$ & SD & & & f & $\%$ & $\mathbf{M}_{\text {age }}$ & SD & & & f & $\%$ & $\mathbf{M}_{\text {age }}$ & SD \\
\hline 12-13 y.o. & & & 727 & 37.92 & 12.49 & 0.50 & & & 776 & 30.12 & 12.55 & 0.50 & & & 1503 & 33.45 & 12.52 & 0.50 \\
\hline $14-15$ y.o. & & & 475 & 24.78 & 14.56 & 0.50 & & & 645 & 25.04 & 14.52 & 0.50 & & & 1120 & 24.93 & 14.54 & 0.50 \\
\hline 16-18 y.o. & & & 715 & 37.30 & 17.02 & 0.82 & & & 1155 & 44.84 & 17.11 & 0.82 & & & 1870 & 41.62 & 17.08 & 0.81 \\
\hline Total & & & 1917 & 100.00 & 14.70 & 2.07 & & & 2576 & 100.00 & 15.09 & 2.07 & & & 4493 & 100.00 & 14.92 & 2.08 \\
\hline \multirow{2}{*}{ Age groups } & \multicolumn{2}{|c|}{$\begin{array}{c}\text { Non- } \\
\text { practitioners }\end{array}$} & \multicolumn{2}{|c|}{ Dropouts } & \multicolumn{2}{|c|}{ Practitioners } & \multicolumn{2}{|c|}{$\begin{array}{c}\text { Non- } \\
\text { practitioners }\end{array}$} & \multicolumn{2}{|c|}{ Dropouts } & \multicolumn{2}{|c|}{ Practitioners } & \multicolumn{2}{|c|}{$\begin{array}{c}\text { Non- } \\
\text { practitioners }\end{array}$} & \multicolumn{2}{|c|}{ Dropouts } & \multicolumn{2}{|c|}{ Practitioners } \\
\hline & f & $\%$ & f & $\%$ & f & $\%$ & f & $\%$ & f & $\%$ & f & $\%$ & f & $\%$ & f & $\%$ & f & $\%$ \\
\hline 12-13 y.o. & 55 & 7.57 & 152 & 20.91 & 520 & 71.53 & 90 & 11.60 & 253 & 32.60 & 433 & 55.80 & 145 & 9.65 & 405 & 26.95 & 953 & 63.41 \\
\hline 14-15 y.o. & 34 & 7.16 & 117 & 24.63 & 324 & 68.21 & 81 & 12.56 & 313 & 48.53 & 251 & 38.91 & 115 & 10.27 & 430 & 38.39 & 575 & 51.34 \\
\hline 16-18 y.o. & 39 & 5.45 & 184 & 25.73 & 492 & 68.81 & 165 & 14.29 & 607 & 52.55 & 383 & 33.16 & 204 & 10.91 & 791 & 42.30 & 875 & 46.79 \\
\hline Total & 128 & 6.68 & 453 & 23.63 & 1336 & 69.69 & 336 & 13.04 & 1173 & 45.54 & 1067 & 41.42 & 464 & 10.33 & 1626 & 36.19 & 2403 & 53.48 \\
\hline
\end{tabular}

f: frequency; \%: percentage; $M_{\text {age }}$ : Mean ages; SD: Standard deviation; y.o.: years old

\section{Measures}

Demographics. Participants provided answers to questions assessing gender, age, school, grade, and hometown. 
Achievement goal orientations. The Task and Ego Orientation in Sports Questionnaire (TEOSQ) for the physical education school context (Walling \& Duda, 1995; Duda, Chi, Newton, Walling, \& Catley, 1995), adapted to Italian culture by Bortoli and Robazza $(2004 ; 2005)$, was used to measure the achievement goal orientations.

The Italian version of the Task and Ego Orientation in Sport Questionnaire (TEOSQ) is a self-report questionnaire that consists of 16 items that can be grouped into two subscales: the ego goal orientation scale and the task goal orientation scale. Answers were given on 5-point scales ranging from 1 (strongly disagree) to 5 (strongly agree), and the internal consistency for both task and ego subscales reported was satisfactory (Cronbach's alpha: ego $=0.92$ and task $=0.84$ ). In our study, the Cronbach's alpha for the ego scale was 0.90 , and that for the task scale was 0.83 .

Perceived Physical Competence. The Italian short form of the Physical Self-Description Questionnaire (PSDQ-S) by Scarpa et al. (2010), adapted from the original English version by Marsh, Martin and Jackson (2010), was administered to measure perceived physical competence.

The Italian PSDQ-S is a self-report questionnaire that measures two global dimensions (self-esteem and physical self-concept) and nine sub-scales of the physical self-concept (health, appearance, body fat, activity, sport, coordination, flexibility, strength, and endurance).

For this study, six of the eleven subscales were used: perceived physical activity, sport, coordination, flexibility, strength, and endurance. Each subscale consists of 4 items, with the exception of strength which consist of 3 items. Each item is a declarative statement (for example, "I am good at most sports") in which the subjects answer using a six-point scale ranging from 1 ("false") to 6 ("true"). The Italian PSDQ-S decreases the extension of the original edition without losing its psychometric properties, with Alpha coefficients from 0.77 to 0.91 . The results of the Cronbach's alpha coefficients in our study ranged from 0.77 to 0.86 .

Physical activity participation. Two questions were used to measure participants' involvement in physical activity outside their school's physical education classes.

Students were given a definition of physical activity as any bodily movement resulting in energy expenditure, including planned, structured, repetitive exercises, sports, or dance (Caspersen, Powell, \& Christenson, 1985).

First, participants were asked if they had practiced physical activity outside the school's physical education lessons in the past six months: the answer options were: $1=$ 'no, I've never practiced physical activity or sport outside school physical education lessons', 2 = 'no, I must leave my practice because...', or 3 = 'yes, I usually practice physical activity or sport outside school physical education lessons'. These responses yielded three groups: $1=$ non-practitioners, $2=$ dropouts (who had not participated in physical activity outside physical education lessons for more than about six months), and $3=$ practitioners.

Second, students involved in physical activity outside school were asked to state how many times per week they exercised or had played a sport in the previous six months. Answer options were 5: $1=$ only physical education (PE) lessons; $2=1$ day per week, outside PE lessons; $3=2-3$ days 
per week, outside PE lessons; $4=4$ days per week, outside PE lessons; $5=5$ or more days per week, outside PE lessons). The answers were used to assess how much outside-school physical activity young people are involved in.

\section{Procedure}

The study was conducted in a collective form after requesting the cooperation of the participating school principals. Before the administration of the questionnaires, the students' parents were asked to complete a consent form and were given general information about the study, objectives, and data collection. The consent forms were delivered to a teacher responsible for distributing and gathering them. Afterwards, the pencil-and-paper questionnaire, including all the measures, was distributed in classroom conditions during normal school hours. Questionnaires were administered by the first author, in a single session for each class. Before completing the questionnaire, the participants were given information about the study objectives, anonymity, and confidentiality of their responses and were allowed to refuse to participate. Then, the participants were instructed on how to fill out the questionnaire and the meaning of physical activity as described in the previous paragraph. After, the students were requested to complete the questionnaires, which took 30 minutes on average.

\section{Statistical analysis}

Means, standard deviations, and Cronbach's alpha values were performed. For the comparisons of the gender groups and the age groups, a one-way analysis of variance (ANOVA) on each dependent variable was calculated. Post-hoc Tukey's Honestly Significant Difference (HSD) tests (Tabachnick \& Fidell, 1989) were used to examine the pairwise comparisons between the age groups. Correlations between all variables were conducted using Pearson's r.

To identify subgroups of adolescents based on achievement goals and perceived competence, a cluster analysis was performed. The two-stage clustering process was used to determine the number of groups by the procedures defined by Hair, Anderson, Tatham, \& Black, 1998. All variables were standardized with their Z-scores due to the fact that PSDQ-S and TEOSQ scores, as well as physical activity frequency, were calculated using different scales and different ranges. Thus, the standardization prevents the variables from contributing in proportional measure to the range of the measuring scale (Everitt, Landau, Leese, \& Stahl, 2011).

The cluster analysis was carried out, including the two dispositional goal orientations (task and ego) and the six subscales of the PSDQ related to the perceived physical competence (strength, coordination, activity, endurance, flexibility, and sport). Physical activity frequency was not included but was used for cluster validation purposes, as argued in cluster analysis studies (Hair et al. 1998).

Ward's method was used in the hierarchical cluster analysis. The analysis of the agglomeration schedule and the dendrogram allowing us to determine a three-cluster solution seems to be appropriate because smaller coefficients indicate more homogeneous clusters are being merged. 
After, a k-means non-hierarchical cluster analysis procedure was used, which allowed us to maximize the relationship between the variability between groups and the variability within a group, which turns out to be very effective in the management of a high number of cases (Barbaranelli, 2006). To obtain the highest efficiency and to further validate the stability of the cluster solution, after the first application, a second k-means cluster analysis was performed. In this stage of the analysis, the initial centroids of the clusters created in the first analysis were used to recalculate cluster analysis. The results confirmed a three-cluster solution was consistent compared to the first stage, in terms of both cluster sizes and profiles

Additionally, to evaluate the predictive validity of the cluster solution, a one-way MANOVA was conducted using age and physical activity frequency as dependent variables and clusters as the independent variable.

Furthermore, we conducted a cluster analysis with the two-stage approach, splitting participants by gender, to explore whether a separated classification was better than a single solution.

\section{Results}

The descriptive statistics and comparisons between genders and among age groups are shown in Table 2. Significant differences were found in all variables. Males and younger participants had higher mean scores than females in task and ego goal orientations and perceived competence. The intercorrelations between all variables are shown in Table 3.

Table 2. Descriptive Statistics and Comparisons between Genders and among Age Groups with Tukey’s HSD

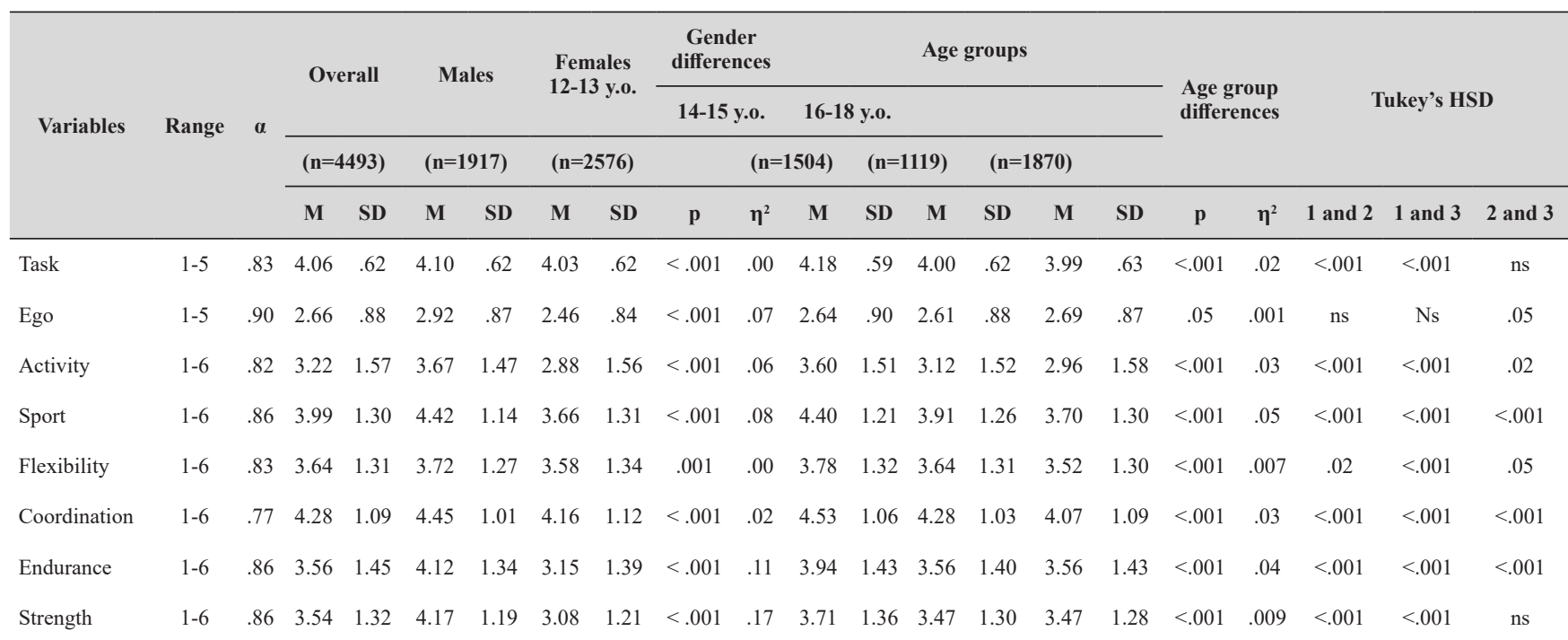

$\mathrm{n}=$ sample group and subgroups size; $\alpha$ : Cronbach's alpha coefficient; M: Mean; SD: Standard deviation; y.o.: years old; Tukey's HSD: Tukey's Honestly significant difference; $\mathrm{p}$ : $\mathbf{p}$-value; $\mathbf{\eta}^{2}$ : eta squared; ns: not statistically significant; 1: first age group (12-13 years old);

2: second age group (14-15 years old); 3: third age group (16-18 years old) 
Table 3. Intercorrelations for all Variables

\begin{tabular}{|c|c|c|c|c|c|c|c|}
\hline Variables & 1 & 2 & 3 & 4 & 5 & 6 & 7 \\
\hline 1. Task & - & & & & & & \\
\hline 2. Ego & $.340^{* *}$ & - & & & & & \\
\hline 3. Activity & $.334^{* *}$ & $.279^{* *}$ & - & & & & \\
\hline 4. Sport & $.463^{* *}$ & $.376^{* *}$ & $.587^{* *}$ & - & & & \\
\hline 5. Flexibility & $.290^{* *}$ & $.251^{* *}$ & $.339^{* *}$ & $.482^{* *}$ & - & & \\
\hline 6. Coordination & $.430^{* *}$ & $.276^{* *}$ & $.440^{* *}$ & $.654^{* *}$ & $.586^{* *}$ & - & \\
\hline 7. Endurance & $.367^{* *}$ & $.324^{* *}$ & $.475^{* *}$ & $.609^{* *}$ & $.416^{* *}$ & $.512^{* *}$ & - \\
\hline 8. Strength & $.270^{* *}$ & $.359^{* *}$ & $.391^{* *}$ & $.521^{* *}$ & $.273^{* *}$ & $.356^{* *}$ & $.449^{* *}$ \\
\hline
\end{tabular}

With respect to the practice of physical activity, $69.7 \%$ of the boys and $41.4 \%$ of the girls were engaged in physical activity outside of required school physical education lessons. $23.6 \%$ of the boys and $45.5 \%$ of the girls had not participated in physical activity outside physical education lessons for more than about six months.

While percentages of males practicing physical activity decreased from $71.5 \%$ at 12 years old to $68.8 \%$ at 18 years old, percentages of females practicing physical activity decreased from $55.8 \%$ at 12 years old to $33.2 \%$ at 18 years old. In parallel, percentages of females who did not practice physical activity increased with age. However, in all ages, the majority of boys and girls of those who did not practice physical activity outside physical education lessons was represented by those who had abandoned physical activity.

A one-way analysis of variance (ANOVA) revealed that, in both genders, physical activity frequency significantly decreased with age (males: $F(6,1906)=4.787 ; \mathrm{p}<.001$; females: $\mathrm{F}(6$, $2557)=29.080 ; \mathrm{p}<.001)$, especially in girls.

Sharing participants by gender, age groups comparisons showed that there were no significant differences in male ego orientation between 12-13 and 14-15 age groups, but significant differences were found among 16-18 age group and the other two groups. Means were significantly higher in 16-18 age group. Female Ego orientation means were not significantly different among the age groups. Task orientation means were significantly higher in 12-13 years old than the other two age groups, in both genders. In males, means were significantly higher in perceived physical activity, sport, and coordination in 12-13 age group than in the other two groups. Endurance means significantly decrease with rising age. In females, the decrease was significant in all the variables between all the age groups, except for strength between 14-15 age group and 16-18 age group. 
Table 4. Descriptive Statistics and Comparisons among Age Groups by Gender

\begin{tabular}{|c|c|c|c|c|c|c|c|c|c|c|c|c|c|c|c|c|c|c|c|c|c|c|}
\hline \multirow{4}{*}{ Variables } & \multicolumn{11}{|c|}{ Males $(n=1917)$} & \multicolumn{11}{|c|}{ Females $(n=2576)$} \\
\hline & \multicolumn{6}{|c|}{ Age groups } & \multirow{2}{*}{\multicolumn{2}{|c|}{$\begin{array}{l}\text { Age group } \\
\text { differences }\end{array}$}} & \multirow{2}{*}{\multicolumn{3}{|c|}{ Tukey's HSD }} & \multicolumn{6}{|c|}{ Age groups } & \multirow{2}{*}{\multicolumn{2}{|c|}{$\begin{array}{l}\text { - Age group } \\
\text { differences }\end{array}$}} & \multirow{2}{*}{\multicolumn{3}{|c|}{ Tukey's HSD }} \\
\hline & \multicolumn{2}{|c|}{$\begin{array}{l}\text { 12-13 y.o. } \\
(n=728)\end{array}$} & \multicolumn{2}{|c|}{$\begin{array}{c}14-15 \text { y.o. } \\
(n=474)\end{array}$} & \multicolumn{2}{|c|}{$\begin{array}{c}\text { 16-18 y.o. } \\
(\mathrm{n}=715)\end{array}$} & & & & & & \multicolumn{2}{|c|}{$\begin{array}{c}12-13 \text { y.o. } \\
(n=776)\end{array}$} & \multicolumn{2}{|c|}{$\begin{array}{c}14-15 \text { y.o. } \\
(n=645)\end{array}$} & \multicolumn{2}{|c|}{$\begin{array}{l}\text { 16-18 y.o. } \\
(n=1155)\end{array}$} & & & & & \\
\hline & M & SD & M & SD & M & SD & $\mathbf{p}$ & $\eta^{2}$ & 1 and 2 & 1 and 3 & 2 and 3 & M & SD & M & SD & M & SD & $\mathbf{p}$ & $\eta^{2}$ & 1 and 2 & 21 and 3 & 2 and 3 \\
\hline Task & 4.20 & .61 & 4.04 & .60 & 4.03 & .62 & $<.001$ & .02 & $<.001$ & $<.001$ & $\mathrm{~ns}$ & 4.17 & .58 & 3.96 & .63 & 3.97 & .64 & $<.001$ & .02 & $<.001$ & $<.001$ & ns \\
\hline Ego & 2.84 & .90 & 2.89 & .87 & 3.03 & .81 & $<.001$ & .01 & $\mathrm{~ns}$ & $<.001$ & .01 & 2.46 & .86 & 2.41 & .83 & 2.48 & .83 & ns & .00 & $\mathrm{~ns}$ & $\mathrm{~ns}$ & ns \\
\hline Activity & 3.85 & 1.43 & 3.57 & 1.45 & 3.54 & 1.50 & $<.001$ & .01 & .003 & $<.001$ & $\mathrm{~ns}$ & 3.36 & 1.54 & 2.80 & 1.50 & 2.60 & 1.52 & $<.001$ & .04 & $<.001$ & $<.001$ & .02 \\
\hline Sport & 4.65 & 1.11 & 4.35 & 1.15 & 4.24 & 1.13 & $<.001$ & .03 & $<.001$ & $<.001$ & $\mathrm{~ns}$ & 4.16 & 1.26 & 3.59 & 1.24 & 3.37 & 1.29 & $<.001$ & .07 & $<.001$ & $<.001$ & .001 \\
\hline Flexibility & 3.77 & 1.28 & 3.69 & 1.26 & 3.69 & 1.25 & $\mathrm{~ns}$ & .00 & ns & $\mathrm{ns}$ & $\mathrm{ns}$ & 3.80 & 1.36 & 3.60 & 1.32 & 3.42 & 1.33 & $<.001$ & .01 & .01 & $<.001$ & .01 \\
\hline Coordination & 4.61 & 1.02 & 4.42 & 0.97 & 4.29 & 1.00 & $<.001$ & .02 & .004 & $<.001$ & ns & 4.46 & 1.09 & 4.18 & 1.06 & 3.94 & 1.12 & $<.001$ & .04 & $<.001$ & $<.001$ & $<.001$ \\
\hline Endurance & 4.33 & 1.34 & 4.12 & 1.30 & 3.91 & 1.33 & $<.001$ & .02 & .007 & $<.001$ & .006 & 3.58 & 1.42 & 3.14 & 1.32 & 2.86 & 1.34 & $<.001$ & .05 & $<.001$ & $<.001$ & $<.001$ \\
\hline Strength & 4.26 & 1.24 & 4.10 & 1.17 & 4.11 & 1.15 & .03 & .004 & ns & ns & ns & 3.21 & 1.27 & 3.00 & 1.19 & 3.03 & 1.18 & .001 & .005 & .004 & .005 & ns \\
\hline
\end{tabular}

$\mathrm{n}=$ sample group and subgroups size; M: Mean; SD: Standard deviation; y.o.: years old; Tukey's HSD: Tukey's Honestly significant difference; $\mathbf{p}$ : $\mathbf{p}$-value; $\boldsymbol{\eta}^{2}$ : eta squared; ns: not statistically significant; 1 : first age group (1213 years old); 2: second age group (14-15 years old); 3: third age group (16-18 years old)

\section{Cluster Analysis}

The results of the k-means cluster analysis showed significant differences among clusters on the dependent variables, Wilks' Lambda $=.731, \mathrm{~F}(4,8932)=378.798, \mathrm{p}<.001 . \eta^{2}=.145$.

Table 5 shows the three-cluster solution of the k-means cluster analysis for males and females, with means, standard deviations, Z-scores, and cluster characteristics. Z-scores greater than \pm 0.50 were used as criteria to describe whether one group has relatively lower or higher scores than the other (Biddle \& Wang, 2003).

Table 5. Means, Standard Deviations, and Z scores for the Three-cluster Solution

\begin{tabular}{|c|c|c|c|c|c|c|c|c|c|c|c|c|c|c|c|c|c|c|}
\hline \multirow{3}{*}{ Variables } & \multicolumn{9}{|c|}{ Males } & \multicolumn{9}{|c|}{ Females } \\
\hline & \multicolumn{3}{|c|}{ Cluster 1: High } & \multicolumn{3}{|c|}{ Cluster 2: Moderate } & \multicolumn{3}{|c|}{ Cluster 3: Low } & \multicolumn{3}{|c|}{ Cluster 1: High } & \multicolumn{3}{|c|}{ Cluster 2: Moderate } & \multicolumn{3}{|c|}{ Cluster 3: Low } \\
\hline & M & SD & Z & M & SD & Z & M & SD & Z & M & SD & Z & M & SD & $\mathrm{Z}$ & M & SD & $\mathbf{Z}$ \\
\hline Task & 4.418 & 0.469 & 0.513 & 4.058 & 0.534 & -0.068 & 3.603 & 0.687 & -0.802 & 4.364 & 0.457 & 0.537 & 4.075 & 0.507 & 0.074 & 3.675 & 0.691 & -0.567 \\
\hline Ego & 3.300 & 0.824 & 0.434 & 2.854 & 0.759 & -0.082 & 2.386 & 0.837 & -0.623 & 2.811 & 0.827 & 0.419 & 2.487 & 0.755 & 0.034 & 2.108 & 0.814 & -0.415 \\
\hline Activity & 4.968 & 0.906 & 0.884 & 3.259 & 1.114 & -0.277 & 2.155 & 0.958 & -1.027 & 4.684 & 0.953 & 1.158 & 2.403 & 1.061 & -0.307 & 1.807 & 0.966 & -0.690 \\
\hline Sport & 5.307 & 0.591 & 0.775 & 4.367 & 0.762 & -0.049 & 2.906 & 0.955 & -1.329 & 4.886 & 0.761 & 0.931 & 3.865 & 0.854 & 0.153 & 2.337 & 0.861 & -1.010 \\
\hline Flexibility & 4.548 & 1.049 & 0.655 & 3.520 & 1.069 & -0.157 & 2.621 & 0.997 & -0.867 & 4.553 & 1.070 & 0.723 & 3.859 & 1.076 & 0.206 & 2.394 & 0.895 & -0.883 \\
\hline Coordination & 5.197 & 0.658 & 0.739 & 4.352 & 0.785 & -0.094 & 3.269 & 0.777 & -1.161 & 5.056 & 0.720 & 0.804 & 4.336 & 0.820 & 0.161 & 3.143 & 0.884 & -0.906 \\
\hline Endurance & 5.102 & 0.830 & 0.730 & 4.043 & 1.047 & -0.061 & 2.491 & 0.971 & -1.219 & 4.280 & 1.145 & 0.813 & 3.278 & 1.097 & 0.094 & 1.981 & 0.899 & -0.838 \\
\hline Strength & 4.733 & 0.980 & 0.476 & 4.082 & 1.068 & -0.070 & 3.298 & 1.241 & -0.728 & 3.913 & 1.094 & 0.689 & 3.109 & 1.022 & 0.026 & 2.292 & 0.980 & -0.648 \\
\hline
\end{tabular}




\begin{tabular}{|c|c|c|c|c|c|c|c|c|c|c|c|c|c|c|c|c|c|c|}
\hline \multirow{3}{*}{ Variables } & \multicolumn{9}{|c|}{ Males } & \multicolumn{9}{|c|}{ Females } \\
\hline & \multicolumn{3}{|c|}{ Cluster 1: High } & \multicolumn{3}{|c|}{ Cluster 2: Moderate } & \multicolumn{3}{|c|}{ Cluster 3: Low } & \multicolumn{3}{|c|}{ Cluster 1: High } & \multicolumn{3}{|c|}{ Cluster 2: Moderate } & \multicolumn{3}{|c|}{ Cluster 3: Low } \\
\hline & M & SD & $\mathbf{Z}$ & $\mathbf{M}$ & SD & $\mathbf{Z}$ & $\mathbf{M}$ & SD & $\mathbf{Z}$ & M & SD & $\mathbf{Z}$ & $\mathbf{M}$ & SD & $\mathbf{Z}$ & M & SD & $\mathbf{Z}$ \\
\hline PA Frequency & 3.377 & 1.172 & 0.561 & 2.366 & 1.232 & $-0,152$ & 1.632 & 1.045 & -0.703 & 2.753 & 1.156 & 0.833 & 1.504 & 0.937 & -0.264 & 1.296 & 0.749 & -0.448 \\
\hline \multicolumn{19}{|c|}{ Cluster Characteristics } \\
\hline Cluster age (\%) & 14.45 & $(2.04)$ & & 14.71 & $(2.03)$ & & 15.13 & $(2.12)$ & & 14.49 & $(2.13)$ & & 15.08 & $(1.98)$ & & 15.64 & $(1.97)$ & \\
\hline Cluster n (\%) & 701 & $(36.61)$ & & 838 & (43.66) & & 378 & $(19.74)$ & & 761 & (29.54) & & 967 & $(37.54)$ & & 848 & $(32.92)$ & \\
\hline Total & 1917 & & & & & & & & & 2576 & & & & & & & & \\
\hline $12-13$ у.о. (\%) & 309 & $(44.08)$ & & 303 & (36.16) & & 116 & (30.69) & & 333 & $(43.76)$ & & 276 & $(28.54)$ & & 167 & (19.69) & \\
\hline $14-15$ у.о. (\%) & 155 & (22.11) & & 232 & (27.68) & & 87 & $(23.02)$ & & 164 & $(21.55)$ & & 274 & $(28.34)$ & & 207 & $(24.41)$ & \\
\hline $16-18$ у.о. (\%) & 237 & $(33.81)$ & & 303 & $(36.16)$ & & 175 & $(46.30)$ & & 264 & (34.69) & & 417 & (43.12) & & 474 & $(55.90)$ & \\
\hline
\end{tabular}

Cluster $\mathrm{n}=$ cluster size; \%: percentage; M: Mean; SD: Standard deviation; Z=Z-score; y.o.: years old; PA Physical Activity; Cluster 1: High task orientation and perceived competence; Cluster 2: Moderate task orientation and perceived competence; Cluster 3: Low task orientation and perceived competence

\section{Profiles of cluster groups}

The first cluster is labeled high task orientation and perceived competence. The boys and the girls belonging to this group had higher levels of task orientation, moderate levels of ego orientation ( $\mathrm{Z}$ score is 0.434 in males and 0.419 in females), and higher perceived competence than the other groups of each gender.

However, the males' cluster showed Z-scores between 0.434 and 0.884 in all the variables and the females' cluster showed Z-scores between 0.419 and 1.158. For both genders, the lowest Z score is in Ego goal orientation and the highest is in the perceived level of activity. This group of boys represents $36.61 \%$ of the male participants $(n=701)$ and $29.54 \%$ of the female participants $(n=761)$.

The achievement goal profile of this group is characterized in males by higher task and ego goal orientations and in females by a high task goal orientation and a moderate ego goal orientation.

The second cluster is labeled moderate task orientation and perceived competence. In males, this group was characterized by moderate levels in all the variables considered, with the exception of ego orientation that is low ( $Z$ score is -0.082 ). $Z$-scores ranging between -0.277 and -0.049 . In the female group, scores were moderate, with Z-scores between -0.307 and 0.026 . While for both genders, the lowest $Z$ score is in the perceived level of activity, the highest $Z$ score is in Sport for males and in Strength for females. This group represents $43.66 \%$ of the male participants and $37.54 \%$ of the female participants.

The third cluster, labeled low task orientation and perceived competence, was characterized by lower levels in all the variables than the other groups. For males the Z-scores vary between 
-1.329 and -0.623 , while for females the Z-scores of the variables range from -1.010 to -0.415 . For both genders, the lowest $Z$-score is in the perceived level of sport competence and highest is in Ego goal orientation.

This cluster represents $19.74 \%$ of the male participants and $32.92 \%$ of the female participants.

\section{Gender, age, and physical activity participation differences in cluster composition}

In the high task orientation and perceived competence profile, practitioners are $33.8 \%$ of males and $25.0 \%$ of females. $12.4 \%$ of males and $24.4 \%$ of females attend only required physical education lessons.

In the moderate task orientation and perceived competence profile, practitioners are $29.2 \%$ of males and $10.8 \%$ of females; $38.9 \%$ of males and $75.8 \%$ of females attend only required physical education lessons.

On the contrary, in the low task orientation and perceived competence profile, $13.0 \%$ of males and $27.2 \%$ of females attend only required physical education lessons. Furthermore, $25.1 \%$ of males and $12.9 \%$ of females practice physical activity outside the required physical education lessons more than twice a week.

Z-scores of physical activity frequency of males' and females' profiles are shown in Table 4.

A complementary MANOVA was conducted to observe the possible differences between genders, age, and physical activity frequency in cluster membership.

Results showed significant differences between genders and among the clusters on the dependent variables (age and physical activity frequency). Results showed that there were significant multivariate effects on genders, Wilks' Lambda $=.931, \mathrm{~F}(2,4463)=164.788, \mathrm{p}<.001 \eta^{2}=0.69$, on clusters, Wilks' Lambda $=.737, \mathrm{~F}(4,8926)=368.074, \mathrm{p}<.001 \eta^{2}=.142$, and on the interactions between genders and clusters, Wilks' Lambda $=.988, \mathrm{~F}(4,8926)=13.203, \mathrm{p}<.001 \eta^{2}=.006$.

Sharing the participants by gender, we conducted a MANOVA to perform a deeper analysis among clusters on age groups and physical activity frequency.

Results showed significant differences in males among the clusters (Wilks' Lambda $=.771 \mathrm{~F}(4$, $3806)=132.316 \mathrm{p}<.001)$; ANOVA for age groups $\left(\mathrm{F}(2,1904)=13.629 \mathrm{p}<.001 \eta^{2}=.014\right)$, and physical activity frequency $\left(\mathrm{F}(2,1904)=257.993 \mathrm{p}<.001 \eta^{2}=.225\right)$.

In females significant differences were found among the clusters (Wilks' Lambda $=.691 \mathrm{~F}(4$, $5118)=259.495 \mathrm{p}<.001)$; ANOVA for age groups $\left(\mathrm{F}(2,2563)=64.417 \mathrm{p}<.001 \eta^{2}=.048\right)$, and physical activity frequency $\left(\mathrm{F}(2,2563)=542.899 \mathrm{p}<.001 \eta^{2}=.298\right)$.

Tukey's Honestly Significant Difference (HSD) tests indicated that the males' Low profile had significantly higher age compared with males' High and Moderate profiles. All the female profiles significantly differ in age, the higher the levels of goals and perceived competence, the younger the group members. The Low profile is composed of older females. 
In both genders, all the clusters significantly differ in physical activity frequency. The higher the levels of goals and perceived competence, the frequency of the practice of physical activity is increased.

\section{Discussion}

This study aimed to identify participants' cluster profiles based on their goal orientations and perceived physical competence in physical education classes. Therefore, we tested the differences between clusters regarding gender, age, and frequency of participation in physical activity outside required school physical education lessons.

The initial hypothesis was that adolescents with higher levels of perceived physical competence and higher task goal orientation are more involved in physical activities outside physical education lessons, compared to their peers who are less involved or are not involved at all in physical activity outside physical education lessons. Furthermore, a second hypothesis was that females have lower levels of perceived competence, goal orientations, and participation in physical activities outside-school physical education than males.

Previous research has demonstrated that motivational processes are complex and cannot be considered as being simply high or low. This study allows us to identify three profiles for both genders: high, moderate, and low task orientation and perceived competence profiles. We assigned the same labels for both genders to provide the relative comparison of the groups in each gender category even though specific differences between girls and boys were found. The cluster analysis in our study confirmed the results of several studies, which addressed three motivational profiles (Wang et al., 2002; Ntoumanis, 2002; McNeill \& Wang, 2005; Moreno Murcia, Cervelló Gimeno, \& González-Cutre Coll, 2007).

Results showed $27.3 \%$ of the participants reflecting a more negative motivational profile $(19.7 \%$ of the males and $32.9 \%$ of the females) and $32.7 \%$ being positive (36.6\% of the males and $29.5 \%$ of the females). As suggested by Wang et al. 2010, also the males' moderate profile could be considered an adaptive pattern, in which group members showed high means also in sport, coordination, endurance and strength. Whereas the females' moderate profile seems to show a less adaptive pattern than the corresponding profile in males. With the exception of task orientation and coordination, indeed, females showed lower levels than males in all the variables.

In all the clusters, the means of task-goal orientation were higher than those of ego orientation, which was moderate in the high task orientation and perceived competence group and low in the two other groups.

In our study, students had lower task orientation $(\mathrm{M}=4.06, \mathrm{SD}=0.62)$ compared to the Spanish sample $(\mathrm{M}=4.28, \mathrm{SD}=0.67)$ in Moreno et al. (2008), the English sample $(\mathrm{M}=4.14, \mathrm{SD}=0.61)$ in Wang et al. (2002) and another 70 studies reviewed in Duda and Whitehead (1998), and had higher task orientation than Chinese students $(\mathrm{M}=3.89, \mathrm{SD}=.64)$ in Wang et al. (2010).

Although in our male sample Ego orientation levels were similar to other cultures, in our female sample, Ego orientation levels were lower also compared to all these samples of different nation- 
ality. This result seems to be consistent with a previous research on an Italian sample of children and preadolescents (Bortoli \& Robazza, 2005).

Furthermore, comparing subscales of PSDQ mean scores with previous research using the same measure, our study findings showed significant differences across genders consistent with other studies on the Italian population (Carraro, Scarpa \& Ventura, 2010) and other cultures (Marsh, Tomás \& Hülya Apçý, 2002). Also, research carried out using different measures, observed similar results (Hayes, Crocker, Kowalski, 1999; Ferreira \& Fox, 2007).

These findings could be due to the emphasis on the achievement of a good evaluation in the school physical education course, as in Chinese students (Wang et al., 2010). Physical education teachers assigning importance to winning, competition, or interpersonal comparison, may weaken the need for competence, autonomy, and affiliation (Ntoumanis, 2002) in females more than in males.

Gender differences in ego orientation and perceived competence could also be explained in terms of gender stereotypes. The social context through gender stereotyping can exert a major influence on these gender differences (Klomsten, Skaalvik, \& Espnes, 2004). The importance assigned to masculine and feminine values within sport and physical education may be explained by social expectations and role models that greatly influence adolescents (Klomsten, Marsh, \& Skaalvik, 2005). Social beliefs and self-perceptions about gender roles are shaped by the contribution of significant others (peers, parents, teachers, coaches) encouraging (or not) participation in sport or physical activity in relation to gender (including for example also the kind of physical activity and whether it is more fitting for a girl or a boy).

With regard to age differences, we tested whether the levels of goal orientations and perceived competence decline with age more in females than in males. Our study findings showed that younger adolescents are more task oriented than older adolescents, confirming previous results reported by Duda and Whitehead (1998). A study with an Italian sample by Bortoli and Robazza (2005) showed that children (8-11 years) were more ego and task oriented than early adolescents (12-14 years). In our study means of task and ego orientation in the first age group were similar compared to the same age group of this study. Furthermore, male Ego orientation means were significantly higher in 16-18 age group than the other two groups. Whereas female Ego orientation means are constant across the age groups. Task orientation means were significantly higher in younger adolescents than the other two age groups, in both genders.

Our results showed that during adolescence, perceived physical competence decreases with age. This is consistent with a systematic review of 64 studies by Babic et al. (2014). In addition, we found that in males, perceived physical activity, sport, and coordination were significantly lower from 14 to 18 years old, whilst endurance means significantly decrease with rising age. Whereas in females, the decrease was significant in all the variables between all the age groups, except for strength, from 14 to 18 years old.

Among clusters, the males' Low profile had significantly higher age compared with males' High and Moderate profiles. While all the female profiles significantly differ in age, the higher the levels of goals and perceived competence, the younger the group members. 
In our study, males participated in physical activity more than females as did younger compared to older research participants. It is noteworthy that $69.7 \%$ of the boys but only $41.4 \%$ of the girls were engaged in physical activity outside physical education lessons. This result confirms the findings obtained by other studies (Whitehead \& Biddle, 2008). In all ages, the majority of boys and girls of those who did not practice physical activity outside physical education lessons was represented by those who have abandoned physical activity.

From early to late adolescence, the dropout rate could be due to an increase in the request of commitment and homework from teachers of other school subjects, and to a change of interests oriented toward other social activities with peers.

Furthermore, participation in physical activity in itself was not coherent with the cluster, but frequency of the involvement in physical activity (times a week) was more related with belonging to the cluster.

Results showed that in both genders, all the clusters significantly differ in physical activity frequency.

The higher the levels of task and ego goals and perceived competence, the more frequent the scheduling of the practice of physical activities outside physical education lessons. In addition, our study showed that to belong to a positive motivational group, it is not sufficient to participate in physical activity, but it would seem to be more likely to practice twice or more a week in addition to physical education lessons.

Instead, dropouts and non-practitioners placed less emphasis on goal orientations and perceived competence than practitioners.

Biddle and Wang (2003) showed that the motivation and self-perception profiles were not reflected in physical activity levels when Z-scores were within the range \pm 0.5 . According to these authors, one reason could be that the motivation variables are assessed in relation to physical education or sports, but adolescents may take part in an activity for reasons unconnected to their motivation for these contexts. Also, students may take part in physical education due to its compulsory nature and because they place more importance on achievement in school.

In our study, Z-scores were within a wider range, but we could propose the same explanation. Participants may have internalized motivation as an effect of an adaptive impact of school education, more than in other cultures, due to, for example, parental influence and not purely because they have a real interest in physical activities (Yli-Piipari, Watt, Jaakkola, Liukkonen, \& Nurmi, 2009).

Furthermore, school contexts in which Physical education teachers do not value cooperation and promote autonomy and social comparison among peers could undermine motivation for physical activity outside required physical education lessons, especially in adolescents with lower levels of actual and perceived physical competence (Ntoumanis, 2002).

Students in the high task orientation and perceived competence group are likely to be the ablest in adapting to its specific environment compared to the other two groups (Wang \& Biddle, 2001). Thus, it is necessary to understand the needs of the other two groups to oppose the decline in physical activity participation. The relationship between goal orientations and perceived physical 
competence in relation with gender and age should be considered. From the educational intervention perspective, to move the students, especially the girls and late adolescents, to the cluster of high motivation one should act within the social context of school physical education.

In particular, looking at gender differences leads to considerations that are associated with the need to establish programs that emphasize gender identity in physical education and sport contexts (Allender et al., 2006).

Promoting a task-goal-oriented climate in the classroom seems to be more functional in affecting goal orientations, particularly a task-goal orientation. This independently of whether students perceive their competences as high or low (Bortoli \& Robazza, 2004). Then, attention should be paid to feedback regarding tasks and abilities, for example, emphasizing skill improvement, fun, and the game (Craft, Pfeiffer, \& Pivarnik, 2003)

Teachers and educators should schedule differentiated activities and enable choices between different physical activities. This leads adolescents toward the discovery of their personal interests, and broadens knowledge and information regarding physical activity practices.

This study has a few limitations. The first is the cross-sectional nature of the study, which does not allow for the way physical self-concept influences the goal orientations in adolescents to be analyzed.

Secondly, this study did not include other theories on motivation in sport, such as the self-determination theory due to a lack of validated instruments in the Italian population at the time of our administration.

Similarly, we did not consider other associated constructs, such as enjoyment, effort, or perseverance, or social variables, such as the motivational climate, coach-athlete relationship, or social comparison.

In future studies, it would be advisable also to assess other social and environmental aspects that were not considered in this study (Biddle \& Wang, 2003).

Additionally, one could also assess the practice of sports activity using a more structured tool, and additional qualitative measures should be used to examine motivational profile in depth (Çağlar \& Aşçi, 2010).

Apart from these limitations, this study identified three groups with different goal orientations and perceived competence profiles related to gender, age, and frequency of physical activity participation. Defining subgroups is helpful to design intervention programs to better target educational needs and achieve learning goals. Physical education teachers and educators should be aware of the multidimensional nature of perceived competence and achievement goals, and their relationships with participation in physical activity. They should focus on each of its dimensions and create a task-oriented climate with a collaborative environment to promote interest and participation in physical activity. 


\section{References}

Allender, S., Cowburn, G., \& Foster, C. (2006). Understanding Participation in Sport and Physical Activity among Children and Adults: A Review of Qualitative Studies. Health Education Research, 21, 826-835. DOI: 10.1093/her/cyl063

Babic, M., Morgan, P., Plotnikoff, R., Lonsdale, C., White, R., \& Lubans, D. (2014). Physical Activity and Physical Self-Concept in Youth: Systematic Review and Meta-Analysis. Sports Medicine, 44(11), 1589-1601. DOI: 10.1007/s40279-014-0229-Z

Barbaranelli, C. (2006). Analisi dei dati con SPSS. II. Le analisi multivariate [Data Analysis with SPSS. II. Multivariate Analysis]. Milano, IT: LED.

Barnett, L. M., Morgan, P. J., van Beurden, E., \& Beard, J. R. (2008). Perceived sports competence mediates the relationship between childhood motor skill proficiency and adolescent physical activity and fitness: a longitudinal assessment. International Journal of Behavioral Nutrition and Physical Activity, 5(1), 40. DOI:10.1186/1479-5868-5-40

Barnett, L. M., Van Beurden, E., Morgan, P. J., Brooks, L. O., \& Beard, J. R. (2009). Childhood Motor Skill Proficiency as a Predictor of Adolescent Physical Activity. Journal of Adolescent Health, 44(3), 252-259. DOI:10.1016/j.jadohealth.2008.07.004

Biddle, S. J. H. \& Wang C. K. J. (2003). Motivation and Self-perception Profiles and Links with Physical Activity in Adolescent Girls. Journal of Adolescence, 26, 687-701. DOI: 10.1016/j.adolescence.2003.07.003

Bortoli, L., \& Robazza, C. (2004). Motivazioni in educazione fisica: orientamento sul compito e orientamento sull'io [Motivation in Physical Education: Task and Ego Orientations]. Educazione Fisica e Sport nella Scuola, 191/192, 14-22.

Bortoli, L., \& Robazza, C. (2005). Italian Version of the Task and Ego Orientation in Sport Questionnaire. Perceptual and Motor Skills, 100, 43-50. DOI: 10.2466/pms.100.1.43-50

Çağlar, E., \& Aşçi, F.H. (2010) Motivational Cluster Profiles of Adolescent Athletes: an Examination of Differences in Physical Self-Perception. Journal of Sports Science \& Medicine, 9, 231-238.

Carraro, A., Scarpa, S., \& Ventura, L. (2010). Relationships between physical self-concept and physical fitness in Italian adolescents. Perceptual and motor Skills, 110(2), 522-530. DOI: 10.2466/PMS.110.2.522-530

Caspersen, C. J., Powell, K. E., \& Christenson, G. M. (1985). Physical activity, exercise, and physical fitness: definitions and distinctions for health-related research. Public Health Reports, 100(2), 126-131.

Cecić Erpič, S. C. (2011). Motivation for physical education: A review of the recent literature from an achievement goal and self-determination perspective. International Journal of Physical Education, 48(2), 2-14.

Craft, L. L., Pfeiffer, K. A., \& Pivarnik, J. M. (2003). Predictors of Physical Competence in Adolescent Girls. Journal of Youth and Adolescence, 32(6), 431-438. DOI: 10.1023/A:1025986318306

Duda, J. L. (1992). Motivation in Sport Settings: a Goal Perspective Approach. In G. Roberts (Ed.), Motivation in Sport and Exercise (pp.57-91). Champaign, IL: Human Kinetics. 
Duda, J. L., \& Whitehead, J. (1998). Measurement of goal perspectives in the physical domain. In J.L. Duda (Ed.), Advances in sport and exercise psychology measurement (pp.21-48). Morgantown: Fitness Information Technology.

Duda, J. L., Chi, L., Newton, M. L., Walling, M. D., \& Catley, D. (1995). Task and Ego Orientation and Intrinsic Motivation in Sport. International Journal of Sport Psychology, 26, 40-63.

Everitt, B. S., Landau, S., Leese, M., \& Stahl, D. (2011). Cluster Analysis. Chichester, UK: John Wiley \& Sons.

Fabbris, L. (1989). L'indagine campionaria: metodi, disegni e tecniche di campionamento. Roma, IT: La Nuova Italia Scientifica.

Ferreira, J. P. L., \& Fox, K. R. (2007). An Investigation into the Structure, Reliability, and Validity of the Physical Self Perception Profile in Non English Speaking Settings. International Journal of Applied Sports Sciences, 19(1).

Gonçalves, C. E., Coelho e Silva, M. J., Cruz, J., Torregrossa, M., \& Cumming, S. P. (2010). The effect of achievement goals on moral attitudes in young athletes. Journal of Sports Science \& Medicine, 9(4), 605-611.

Hair, J.F.J., Anderson, R.E., Tatham, R.L., \& Black, W.C. (1998). Multivariate Data Analysis. Englewood Cliffs, NJ: Prentice Hall.

Hayes, S. D., Crocker, P. R., \& Kowalski, K. C. (1999). Gender differences in physical selfperceptions, global self-esteem and physical activity: Evaluation of the physical selfperception profile model. Journal of Sport Behavior, 22(1), 1.

Hodge, K., \& Petlichkoff, L. (2000). Goals Profiles in Sport Motivation: A Cluster Analysis. Journal of Sport \& Exercise Psychology, 22, 256-272. DOI: 10.1123/jsep.22.3.256

Khodaverdi, Z., Bahram, A., \& Robinson, L. E. (2015). Correlates of Physical Activity Behaviours in Young Iranian Girls. Child: Care, Health \& Development, 41(6), 903-910. DOI: 10.1111/ cch. 12253

Klomsten, A. T., Marsh, H. W., \& Skaalvik, E. M. (2005). Adolescents' perceptions of masculine and feminine values in sport and physical education: A study of gender differences. Sex roles, 52(9-10), 625-636.

Klomsten, A. T., Skaalvik, E.M., \& Espnes, G. (2004). Physical self-concept and sports: Do gender differences still exist? Sex Roles, 50, 1, 119-127.

Marsh, H. W. (2007). Self-Concept Theory, Measurement and Research into Practice: The Role of Self Concept in Educational Psychology. London, UK: British Psychological Society.

Marsh, H. W., Martin, A. J., \& Jackson, S. (2010). Introducing a short version of the physical selfdescription questionnaire: new strategies, short-form evaluative criteria, and applications of factor analyses. Journal of Sport and Exercise Psychology, 32(4), 438-482.

Marsh, H. W., Tomás Marco, I. \& Hülya Apçý F. (2002). Cross-Cultural Validity of the Physical Self-Description Questionnaire: Comparison of Factor Structures in Australia, Spain, and Turkey. Research Quarterly for Exercise and Sport, 73(3), 257-270. DOI: 10.1080/02701367.2002.10609019

Martins, J., Marques, A., Peralta, M., Palmeira, A., \& da Costa, F. C. (2017). Correlates of Physical Activity in Young People: A Narrative Review of Reviews. Implications for Physical Education Based on a Socio-Ecological Approach. Retos: Nuevas Perspectivas de Educación Física, Deporte y Recreación, 31, 292-299. 
McNeill, M.C., \& Wang, C. K. J. (2005). Psychological Profiles of Elite School Sports Players in Singapore. Psychology of Sport and Exercise, 6, 117-128. DOI:10.1016/j. psychsport.2003.10.004

Moreno Murcia, J. A., Hellín, P., Hellín, G., Cervelló, E., \& Sicilia, A. (2008). Assessment of Motivation in Spanish Physical Education Students: Applying Achievement Goals and Self-Determination Theories. The Open Education Journal, 1, 15-22. DOI: 10.2174/1874920800801010015

Moreno Murcia, J. A., Llamas, L. S., \& Ruiz, L. M. (2006). Perfiles motivacionales y su relación con la importancia concedida a la Educación Física. Educational Psychology, 12(1), 49-63.

Moreno Murcia, J.A., Cervelló Gimeno, E., \& González-Cutre Coll, D. (2007). Young athletes' motivational profiles. Journal of Sports Science \& Medicine, 6, 172-179.

Mouratidou, K., Goutza, S., \& Chatzopoulos, D. (2007). Physical education and moral development: An intervention programme to promote moral reasoning through physical education in high school students. European Physical Education Review, 13(1), 41-56. DOI: $10.1177 / 1356336 X 07072675$

Nicholls, J. G. (1989). The competitive ethos and democratic education. Cambridge, MA: Harvard University Press.

Ntoumanis, N. (2002). Motivational Clusters in a Sample of British Physical Education Classes. Psychology of Sport and Exercise, 3(3), 177-194. DOI: 10.1016/S1469-0292(01)00020-6

Papaioannou, A., \& MacDonald, A. I. (1993). Goals Perspectives and Purposes of Physical Education as Perceived by Greek Adolescents. Physical Education Review, 16, 41-48.

Piercy, K. L., Dorn, J. M., Fulton, J. E., Janz, K. F., Lee, S. M., McKinnon, R. A., ... \& LavizzoMourey, R. (2015). Opportunities for Public Health to Increase Physical Activity Among Youths. American Journal of Public Health, 105(3), 421-426.

Ring, C., \& Kavussanu, M. (2018). The impact of achievement goals on cheating in sport. Psychology of Sport \& Exercise, 35, 98-103. DOI: 10.1016/j.psychsport.2017.11.016

Roberts, G. C., Treasure, D. C., \& Conroy, D. E. (2007). Understanding the Dynamics of Motivation in Sport and Physical Activity: An Achievement Goal Interpretation. In: G. Tenenbaum \& R. C. Eklund (Eds.), Handbook of Sport Psychology (pp. 3-30). Hoboken, NJ: John Wiley \& Sons Inc.

Scarpa, S., Gobbi, E., Paggiaro, A., \& Carraro, A. (2010). Un contributo alla validazione italiana del Physical Self-Description Questionnaire Short [A Contribution to the Italian Validation of the Physical Self-Description Questionnaire Short]. Giornale Italiano di Psicologia dello Sport, 8, 25-30.

Sterdt, E., Liersch, S., \& Walter, U. (2014). Correlates of Physical Activity of Children and Adolescents: A Systematic Review of Reviews. Health Education Journal, 73(1), 72-89. DOI: $10.1177 / 0017896912469578$

Stodden, D. F., Goodway, J. D., Langendorfer, S. J., Roberton, M. A., Rudisill, M. E., Garcia, C., \& Garcia, L. E. (2008). A developmental perspective on the role of motor skill competence in physical activity: An emergent relationship. Quest, 60(2), 290-306. DOI: 10.1080/00336297.2008.10483582

Tabachnick, B.G., \& Fidell, L.S. (1989). Using Multivariate Statistics. New York: Harper Collins. 
Walling, M. D., \& Duda, J. L. (1995). Goals and Their Association With Beliefs About Success in and Perceptions of the Purpose of Physical Education. Journal of Teaching in Physical Education 14, 140-156.

Wang, C. K. J., \& Biddle, S. J. H. (2001). Young People's Motivational Profiles in Physical Activity: A Cluster Analysis. Journal of Sport \& Exercise Psychology, 23(1), 1-22. DOI: 10.1123/jsep.23.1.1

Wang, C. K. J., Chatzisarantis, N. L. D., Spray, C. M., \& Biddle, S. J. H. (2002). Achievement Goal Profiles in School Physical Education: Differences in Self-Determination, Sport Ability Beliefs, and Physical Activity. British Journal of Educational Psychology, 72(3), 433-445. DOI: 10.1348/000709902320634401

Wang, C. K. J., Liu, W. C., Sun, Y., Lim, B. C., \& Chatzisarantis, N. L. (2010). Chinese Students' Motivation in Physical Activity: Goal Profile Analysis using Nicholl's Achievement Goal Theory. International Journal of Sport \& Exercise Psychology, 8(3), 284-301. DOI: 10.1080/1612197X.2010.9671954

Wentzel, K. R. (1991). Social Competence at School: Relations Between Social Responsibility and Academic Achievement. Review of Educational Research, 61, 1-24. DOI:/10.3102/00346543061001001

Whitehead, S., \& Biddle, S. (2008). Adolescent Girls' Perceptions of Physical Activity: A Focus Group Study. European Physical Education Review, XIV(2), 243-262. DOI: 10.1177/1356336X08090708

Yli-Piipari, S., Watt, A., Jaakkola, T., Liukkonen, J., \& Nurmi, J. (2009). Relationships Between Physical Education Students' Motivational Profiles, Enjoyment, State Anxiety, and SelfReported Physical Activity. Journal of Sports Science \& Medicine, 8(3), 327-336.

Zurita-Ortega, F., Alvaro-Gonzalez, J. I., Castro-Sanchez, M., Knox, E. C., Muros, J. J., \& VicianaGarofano, V. (2016). The Influence of Exercise on Adolescents Self-Concept. International Journal of Sport Psychology, 47 (1), pp. 67-80. DOI: 10.7352/IJSP 